\title{
Las poéticas de Beatriz Vallejos y Juan L. Ortiz: una lectura de la diáspora zen
}

\author{
Abigail Raynoldi ${ }^{\bullet}$ \\ Universidad Nacional del Litoral
}

\begin{abstract}
Resumen
El presente trabajo, en sus diferentes momentos, tiene como reunión la poesía. Se considera la perspectiva comparada como una oportunidad única, como dice Franco Carvalhal, para escenificar «interrelaciones culturales y literarias» entre postulados del budismo zen, la poesía japonesa haiku y las poéticas de dos escritores de nuestra zona: un pasaje rápido por el referente entrerriano Juan L. Ortiz y principalmente la poeta santafesina, Beatriz Vallejos.
\end{abstract}

\section{Palabras clave:}

estudios comparados · Juan L. Ortiz · Beatriz Vallejos · poesía japonesa $\cdot$ budismo zen

\begin{abstract}
This work is, at every step, aimed at poetry. A comparative perspective is considered to be one unique opportunity to represent, as Franco Carvalhal says, "cultural and literary interrelations» between hypotheses of Zen Buddhism, Japanese poetry haiku and the poetry of two local writers: a fast description of Juan L. Ortiz, our guide from Entre Ríos, and mainly Beatriz Vallejos, the poet from Santa Fe.

\section{Key words:}

- Comparative studies · Juan L. Ortiz · Beatriz Vallejos - Japanese poetry · Zen Buddhism
\end{abstract}


si nos rozara (y cuánto nos roza) devendriamos al instante lo que siempre fuimos,

somos.

REYNALdo JimÉnEZ

\section{La diáspora y la hospitalidad}

Nuestro itinerario por las poéticas de los escritores de la zona Beatriz Vallejos (Santa Fe, 1922-Rosario, 2007) y Juan Laurentino Ortiz (Puerto Ruiz, 1896-Paraná, 1978) no interroga por una pureza regional o nacional literaria sino que, por el contrario, le interesa «leer lo local en contrapunto, o en redes, con lo mundial» (Gramuglio, 2009: 21). Susana Romano Sued afirma que las entidades de la tradición, la memoria y la historia cultural se sustentan en concepciones de lo "propio", lo «otro", «identidad», «diferencia», como una necesidad de delimitar la pertenencia y la pertinencia de los mundos propios y ajenos, de establecer los límites identificatorios y sus señas, atribuyendo y reconociendo lo que es de uno y de otro. La pregunta que nos extrapola de esta visión sesgada tiene que ver con en qué medida es importante la condición de original, de origen; cuán nacional puede ser una teoría o una idea; cuánto de «influencias» ajenas tiene una obra local (Romano Sued, 2002: 160). Así,

si entendemos la cultura de una comunidad, de una nación, como resultante de procesos diversos de incorporación de factores de distinta y múltiple procedencia, y que lo que la hace propia es justamente los modos particulares que una comunidad tiene para transitar esos procesos, entonces, el combate por la autonomía, la pureza, la originalidad absoluta, deja de tener sentido (2002: 161).

Dentro de la circunscripción literaria también resulta agotadora e infructuosa la pretensión del supuesto original ya que «la literatura es ese territorio flexible que proporciona el lugar de las más inesperadas relaciones y los más paradojales encuentros en todo instante (...)» (Romano Sued, 1995: 56). «La literatura alberga la diáspora de la escritura», esa transmisión de contenidos y formas de otros idiomas. «Se podría pensar que una lengua sólo alcanza su plenitud cuando es capaz de incluir en sí muchas otras, cuando tiene los órganos para asimilar, haciéndolas suyas, esencias extrańas» (1995: 56). Lo interesante de este desplazamiento de elementos, ya pensándolos como culturales y literarios, es ver cómo cada cultura o literatura labra su apropiación o transformación al incorporarlos. La «hospitalidad ${ }^{1}$ del gesto hace que existan poéticas — como las que nos convocan - que en su territorio textual amparan diversas filiaciones o redes con otros universos lingüísticos y/o literarios. El doble tráfico, dispersión y apropiación, dialoga en una frontera no fija, en límites que discurren y se corren provocando lindes permeables, porosos. Nuestra lectura se acerca a los bordes, a la vecindad provocada entre la diáspora de una tradición literaria japonesa, y el hallazgo de algunas de sus particularidades textuales en las poéticas de Juan L. Ortiz, y principalmente, Beatriz Vallejos. Situamos 
el recorrido en «redes transnacionales», indagando en las articulaciones de lo local con lo universal y teniendo en cuenta que, cada obra contiene y organiza su propia poética y espera lectores que activen los hilos intertextuales (Crolla, 2005: 74).

\section{Poesía y silencio}

La poesía, más cerca del orden de lo sensorial, no se apura frente a «las exigencias de la comunicación inmediata donde el lenguaje es instrumento para algo que sucede fuera» (Genovese, 2011: 15). De la ilusión de transparencia y pragmatismo, la poesía se aleja planteando otras singularidades de experiencias con lo real. Con una apariencia de distracción, de ineficacia (2011: 16), una de sus mayores labores es su posibilidad de significar en el silencio, en el espacio blanco circundante. «Tomo del silencio las palabras que me son necesarias» manifestaba Beatriz Vallejos (Vallejos, 2012: 300), con la evidencia del lenguaje poético como aquel que tensa lo percibido, como ese discurso que, frente a la valoración social de la elocuencia, acepta la mudez (Genovese, 2011:17).

La poesía en su práctica, en su hacer desplazado, recupera el silencio, como si fuese un grado cero de lo dicho, y, a la vez, ese silencio necesita el regreso a un grado cero de la normatividad lingüística. Un vacío creado para encontrar el propio ritmo, la propia sintaxis, la puntuación dentro de la cual respirar y el tono, esa cámara de resonancia de la subjetividad. Ese silencio, esa introspección radicalizada, en esa mudez, la inactualidad del discurso poético frente a los otros discursos (2011: 17).

«Me ciño tanto que quizás algún día me quede callada» (Vallejos, 2012: 308). Nacido de la palabra, el poema desemboca en algo que la traspasa, reflexiona Octavio Paz (Paz, 1972: 111). Un trazo de lenguaje que, al albergar su resto, su propio suplemento, su parte inasible de sentido (Dalmaroni, 2009: 1), dilata el significado, extiende el eco de su vacío: «el poema es una careta que oculta el vacío» (Paz, 1972: 13).

\section{Zen y haiku}

Históricamente, el Zen se configuró como una fase ulterior del primitivo Budismo hindú que tenía como líder fundador al gran Buda Sakyamuni (Suzuki, 2014: 37-38). Pasado el tiempo, los líderes budistas de China y Japón aplicaron los principios de su fe a las condiciones de vida y necesidades religiosas del pueblo. Esta readaptación amplió más la brecha entre el Budismo inicial y el Zen posterior, aunque Suzuki expresa que quienes quieren manifestar que éste último se desvincula de su origen deben pensar que todo aquello que es un organismo vivo no queda jamás en el mismo estado de existencia y atraviesa muchas etapas del devenir: 
El denominado Budismo primitivo es la semilla; por ésta nació el Budismo del Lejano Oriente con la promesa de un desarrollo aún mayor (...). Entre las muchas sectas budistas que surgieron, especialmente en la China y el Japón, descubrimos un orden único que proclama la transmisión de la esencia y espíritu del Budismo directamente desde su autor (...). Este orden es uno de los aspectos más significativos del Budismo (...). La «Doctrina del corazón-de-Buda» es su nombre escolástico, pero se conoce más concretamente como «Zen» (2014: 37-38).

La línea Mahayana, de la que proviene la secta que nos preocupa, proclama que todos están dotados de la naturaleza de Buda y/o que todos pueden convertirse en Buda. Una diferencia importante en el camino de la indagación por la trascendencia espiritual ${ }^{2}$ destacado por su practicidad. El Zen, «meditación», propone la experiencia personal como esencial puesto que es individual la percepción del «satori». El satori es una «súbita luz mental que ilumina la nueva verdad, esa que nunca pudo concebirse porque se lo impedía la barrera de preconceptos, de los contenidos intelectuales» (Wolpin, 1998: 8). Concebido como el desapego de la tiranía del intelecto y del racionalismo, del despotismo del ego, el satori se da en el hallazgo de una nueva naturaleza del Yo. Vinculado a una emancipación espiritual, en él no existe más el tormento, la atadura de los pensamientos o sentimientos, la prisión de las circunstancias. Estado en el que se capta la vida tal cual ésta fluye, y se la debe vivir como un pájaro vive en el aire, sin intelectualizar su vuelo sino de manera orgánica y espontánea. Vivir el Zen es poseer una nueva percepción interior de la realidad y un retorno al hogar original, al Yo real, sin nudos con lo terrenal (Suzuki, 2014: 72, 76, 83, 118).

Matsuo Bashō (1644-1694), uno de los principales poetas del haiku, apuntaba en su Libreta de Mochila: «nada de lo que se anota es valioso si no es visto con ojos nuevos» (Genovese, 2011: 127). Percepción re-creada, ligada a la experiencia del satori. El haiku como lo que sucede "aquí y ahora» capta la visión del instante en el que la vida, el universo fluye. Su escritura apuntaba al núcleo vital de la vida zen ya que se equiparaba «vivir el Zen» con «vivir la poesía». Poesía como un camino hacia el centro del ser (Wolpin, 1985: 17), un sendero para develar aquello que siempre estuvo delante ${ }^{4}$. El conocimiento poético representa una verdadera comunión del espíritu con las cosas. Haiku y satori conjugan el momento en que el factor externo e interno se funden 5 .

Haiku, un «acontecimiento breve» donde el significado no es espeso ni rico, «y lo único que se puede hacer es repetirlo", menciona Barthes. No admite comentario, por el contrario, su constituyente es el «vacío de la palabra», el suspenso del lenguaje ${ }^{6}$ (Barthes, 1991: 10).

Una flor diurna/ cierra sus pétalos/ como si rezara. Takashi. (Wolpin 1985: 114)

Mirar lo que el poema señala, leer una impresión. Lo universal que está en nosotros con lo universal que está en el mundo se reúnen configurándonos como parte de algo más que nos abarca y sobrepasa. Nuestro único trabajo: asistir a una experiencia. 


\section{Juan L. Ortiz y la experiencia con el universo}

Un «caso extraordinario de articulación fuerte de lo local con lo universal» (Gramuglio, 2009: 22) lo es el entrerriano Juan Laurentino Ortiz. En toda su poética manifiesta claras filiaciones con la escritura y tópicos orientales. Su texto Fui al río... patentiza la experiencia zen:

Fui al río, y lo sentía/ cerca de mí, enfrente de mí. / Las ramas tenían voces/ que no llegaban/ hasta mí. / La corriente decía/ cosas que no entendía. / Me angustiaba casi./ Quería comprenderlo,/ sentir qué decía el cielo vago y pálido en él/ con sus primeras sílabas alargadas,/ pero no podía./ Regresaba/ _ ¿Era yo el que regresaba?_- en la angustia vaga/ de sentirme solo entre las cosas últimas y secretas./ De pronto sentí el río en mí,/ corría en mí/ con sus orillas trémulas de señas,/ con sus hondos reflejos apenas estrellados. / Corría el río en mí con sus ramajes. / Era yo un río en el anochecer, / y suspiraban en mí los árboles, / y el sendero y las hierbas se apagaban en mí. / Me atravesaba un río, me atravesaba un río! (Ortiz, 2006: 154)

Los primeros versos anudados a la angustia de la voz poética, sufriente por su incomunicación con el lenguaje de la naturaleza, del río. Una creencia de que allí había sentidos para desvestir intelectualmente: «Me angustiaba casi. / Quería comprenderlo». Para el Zen la angustia exterioriza la atadura del Yo asentado en el ego, aferrado a cuestiones mundanales, esclavizado por la lógica racional. En esta indagación, la voz poética atiende a que su vínculo con el universo no es puro y, que para ingresar en una unión orgánica y comprender al río, «debía serlo» ${ }^{7}$. El objetivo es ir sin amarras a las experiencias del nuevo lazo con el universo y es preciso rechazar toda lógica racional para lograrlo. «De pronto» aconteció el satori. Suzuki explica que cuando la mente humana está lista para el satori, éste cae sobre uno por doquier, «un sonido inarticulado, una flor que brota, o un incidente trivial, son la condición que abrirá la mente al satori» (Suzuki, 2014: 117-118). El texto exhibe el desenlace de amalgama total con el universo: «era yo un río al anochecer».

\section{Beatriz Vallejos, tan de aquí que parecía de otra parte}

También constituida como una articulación fuerte de lo local con lo universal, la poética de Beatriz Vallejos evidencia filiaciones con Juan L. Ortiz y los poetas orientales trazando un paisaje de nominaciones e influencias con los que fija las cuentas escriturarias de su Collar de arena (2012): "No sé cuándo ese collar tendrá su último poema», "cada nuevo libro es un enhebrarse en el mismo hilo» (Vallejos, 2012: 303, 307).

Un verso de Juan L. Ortiz (“¿qué significa el cerco crepuscular...?») desemboca en un poema bautizado con el nombre del autor: 


\section{Juan L. Ortiz}

Qué significa la luz, a esta hora/ que se detiene al puente de/ los llamados de los remansos;/ el lado de sí que traía la lejanía / todo el rosado y el lila percibidos/ no de la convicción de los sentidos/ sino de algo que por sí ascendía y/ entrara a la danza de las pausas/y nada fortuito aconteciera al hilar/ de las sedosas reminiscencias de los/ ademanes de la invocación, ah/ callada, silenciosa receptora de las/ señales del aire, a esos cielos, a esa/ hora de ángeles. (2012: 132)

De modo similar a Ortiz, el despertar zen también se evidencia en la escritura de Vallejos. En Está de seibo la sombra del timbó (1987) leemos al final del poema Pasión del jacarandá

\section{-lejanías/ no tengo nombre soy/ este atardecer. (Vallejos, 2012: 180).}

anexándose así al verso: «era yo un río en el anochecer». En el prólogo a El zen en la literatura y la pintura de Samuel Wolpin, la escritora sentencia con palabras de Toho: «haiku es unirse a las cosas y sentir su naturaleza profunda» (Wolpin 1985: 6). Posesión de un saber sobre lo poético y lo vital: «soncco del árbol bello/ no sabe que es azul/ tampoco sabía yo/ que mi corazón es/ un poblado de luciérnagas» (Vallejos, 2012: 197).

La «humildad zen» es una posición de aprendizaje frente a la naturaleza. Los principales maestros dijeron que todo poema debe ser siempre espontáneamente nuevo: «aprende de los pinos, aprende de los bambúes. Aprender: eso es haiku (...)» (Wolpin, 1985: 6). «Maestros maestros son los árboles» (Vallejos, 2012: 228) enuncia Vallejos en Donde termina el bosque sujetando su poética con la existencia, con la humildad zen como gesto hacia el rostro del universo:

Lo insólito de la existencia está ahí, en esa escudilla rota donde florece un loto. Y toda la existencia se comprueba porque la poesía es camino de conocimiento y vida ella misma. Porque hay un principio ético inmutable: el de la suprema humildad. (1985: 6)

«El poema es la instantaneidad perdurable» (Vallejos, 2012: 303). Brevedad atemporal del haiku, como en Ventana: «el rostro de la noche/ madreselvas/ cómo florece el cielo» (2012: 197). Aunque en lo formal tiene más sílabas que un haiku, en su esencia "es un haiku». Y las palabras como presencias, no como amontonamiento de signos, señalan una Naturaleza manifestada no como evasión ${ }^{9}$ sino como encuentro. 


\section{Conclusión}

Recuperando los motivos iniciales, el trabajo tuvo como reunión la "poesía». Y el dispositivo de lectura de los estudios comparados nos posibilitó entender los movimientos de la «diáspora» de elementos del Zen y la poesía del haiku japonés y la «hospitalidad» de las poéticas de Juan L. Ortiz y Beatriz Vallejos al incorporar y reelaborar su influjo en textualidades locales. Qué articulaciones con lo universal tenían nuestros poetas fue el justificativo de estas páginas. Y cómo no, Vallejos condensa y sintetiza: «Una vez pensé de alguien que era enraizado y libre a la vez, transparente y a veces, ¿por qué no? algo entoldado. Y quiero para mí esta conclusión: Era tan de aqui que parecía de otra parte" (Vallejos, 2012: 304).

\section{Notas}

${ }^{1}$ La diáspora entonces es la llave de la transmisión literaria. Sería del todo imposible pensar cabalmente una literatura encerrada en sus fronteras monolingües: ello significaría la extinción de la literatura, tanto por su falta de transmisión hacia afuera (el elemento diaspórico), como por la ausencia de hospitalidad hacia adentro, sumida en una suerte de solipsismo con el consiguiente estancamiento del universo literario (Romano Sued, 1995: 13)

${ }^{2}$ Práctico en relación a la concepción hinduista. Suzuki alega que el misticismo de los hindúes es (...) demasiado complicado y, más aún, no parece tener ninguna relación real ni vital con el mundo práctico de particularidades en el que vivimos. El misticismo del Lejano Oriente -el Zen- es, por el contrario, práctico y sorprendentemente simple. (Suzuki, 2014: 43)

${ }^{3}$ Naturalmente, el zen halla su más dispuesta expresión en la poesía que en la filosofía porque tiene más afinidad con el sentimiento que con el intelecto; su predilección poética es inevitable (Suzuki, 2014: 150).

${ }^{4}$ En este sentido, Aldo Pellegrini reflexiona que no existe nada en la naturaleza que esté exento de poesía, pero aún así, se interroga en qué consiste esa extrańa cosa que existe en todas partes, que está a la vista pero sin embargo no resulta visible para todo el mundo (Wolpin, 1985: 12-14). ${ }^{5}$ El Zen es el océano, el Zen es el aire, el Zen es la montańa, el Zen es el trueno, y el relámpago, la flor primaveral, el calor estival y la nieve invernal; es más, mucho más que esto: el Zen es el hombre. Cuando se llega a entender la humilde flor agrietada en la pared, se entiende el universo y todas las cosas que están en él y fuera de él. (Suzuki, 2014: 55, 77)

${ }^{6} \mathrm{El}$ haiku reproduce el gesto indicativo del niño pequeño que muestra con el dedo cualquier cosa (el haiku no tiene acepción de sujetos), diciendo tan solo: ¡esto!, ¡mirá allá!, ¡oh!, ¡ah! (Carreras, 2014: 9). 
${ }^{7}$ Esto tiene estrecha relación con la tradición narrativa taoísta. Entre los muchos relatos, hay dos, el del pintor dragón y el del arpista que, en su contenido, señalan que es preciso que para llegar a un producto artístico perfecto, acabado, en consonancia con el universo, es fundamental volverse, ser aquello que se pretende expresar. En el primer cuento, el artista, para pintar un dragón, debió volverse dragón. En el segundo, el arpista logró sacar el mejor y más perfecto sonido de aquel arpa porque se olvidó de sí mismo y simplemente ejecutó aquello que el arpa deseaba (Wolpin, 1985: 105). Vemos así el ceñido nexo entre arte y existencia, dos caras de una misma moneda.

${ }^{8}$ (...) no amontonaban palabras ni discursos sino que el poema estaba ahí, inamovible, como una presencia. (Garbatzky, 2004)

9 A la obra de Beatriz Vallejos la llamaban "paisajista» pero ella aclara que su paisajismo no es evasión sino encuentro (Vallejos, 2012: 292).

\section{Referencias bibliográficas}

Barthes, R. El imperio de los signos. [Recuperado en línea]. Consultado el 10 de abril de 2017 en: https://es.scribd.com/doc/102296908/RolandBarthes-El-imperio-de-los-Signos

Carrera, A. (Trad.) (2013). Haikus de las cuatro estaciones. Buenos Aires: Interzona.

Crolla, A. (2005). La verdad de Sancho Panza, «traductor» del Quijote. El Hilo de la Fábula (5). Santa Fe: Universidad Nacional del Litoral.

Dalmaroni, M (2009). Lo que resta (un montaje). En Contratiempos de la memoria en la literatura argentina. La Plata: Universidad Nacional de La Plata.

Duthie, T. (2008). Poesía clásica japonesa. Madrid: Ed. Trotta.

Franco Carvalhal, T. (2006). Lo propio y lo ajeno, ensayos de literatura comparada. Páginas 13-57. Lima: Fondo Editorial de la Universidad Católica Sedes Sapientiae.

Garbatzky, I. (2004) Beatriz Vallejos: Somos una vibración infinita. [Recuperado en línea] http://archivo.lacapital.com.ar/2004/10/10/seniales/ noticia_139292.shtml Consultado el 10 de abril de 2017

Genovese, A. (2011). Leer poesía: lo leve, lo grave, lo opaco. Buenos Aires: Fondo de Cultura Económica.

Gramuglio, Ma. T. (2009). Interrelaciones entre literatura argentina y literaturas extranjeras. Debates actuales e hipótesis de trabajo. El Hilo de la Fábula (8/9). Santa Fe: Universidad Nacional del Litoral.

Jiménez, R. (2008). Ganga. Buenos Aires: Editorial Limón.

Ortiz, J.L. (2006). Obra completa. Santa Fe: Ediciones UNL.

PAz, O. (1972). El arco y la lira. México: Fondo de Cultura Económica. Pellegrini, A. La conquista de lo maravilloso. [Recuperado en línea] http://www.festivaldepoesiademedellin.org/es/Diario/Pellegrini.html Consultado el 10 de abril de 2017 
Romano Sued, S. (1995). El dilema de la traducción y la diáspora de la escritura. Conicet. [Recuperado en línea]. http://www.conicet.gov.ar/wpcontent/uploads/destacadas-divulgacion/2013/05/Template-gacetilla-eldilema-de-la-traducci\%C3\%B3n-y-la-di\%C3\%A1spora-de-la-escritura. pdf Consultado el 10 de abril de 2017

(2003). Mundos propios, voces ajenas: la otredad y la identidad en la traducción. El Hilo de la Fábula (no 2/3). Santa Fe: Universidad Nacional del Litoral.

Suzuki, D.T. (2003). Introducción al budismo zen. Buenos Aires: Ed. Kier. VALLejos, B. (2012). El collar de arena (obra reunida). Rosario: Editorial Municipal de Rosario-Ediciones UNL.

Wolpin, S. (1985). El zen en la literatura y la pintura. Buenos Aires: Editorial Kier.

\section{Raynoldi, Abigail}

